\title{
Der alte Herr Oberförster
}

Liebe Leserinnen, liebe Leser,

zunächst eine Geschichte: Vor reichlich siebzig Jahren im Frühling, hatten wir, mein Freund F. und ich, an einer Waldquelle gezeltet, unsere Suppe gekocht und uns abends am Lagerfeuer Geschichten erzählt. Nach einer kühlen Nacht und einem kleinen Frühstück am Morgen waren wir nun auf dem Heimweg. Er führte über eine flache Bergwiese. Es war frisch. Wir hüpften vor Lebenslust. Die Wiese war mit einzelnen jungen Bäumchen bestandenen. Die waren im Vorjahr noch gewässert worden. So dass an den Stämmchen Gras hoch gewachsen und über den Winter dürr und trocken geworden war. Da fielen dem F. die vom Lagerfeuer-Zündeln noch übrigen Streichhölzer in seiner Hosentasche ein. Im Übermut zündete er ein Grasbüschel an. Ich erschrak, sprang hinzu und trat das Feuer aus. Er zündete das nächste Büschel an; ich sprang und trat es aus. So ging es weiter: er jauchzend und spottend, von Bäumchen zu Bäumchen spurtend; ich verbissen und schimpfend hinter ihm her; immer weiter, bis ihm endlich die Zündhölzer ausgingen. Eine verrückte Szene.

Soweit das real Erlebte. Ich stelle mir nun dazu vor, dass unter den Buchen am Wiesenrande der alte Oberförster stand und uns beobachtete. Warum aber hat er mir nicht geholfen? Er hätte sich ja für seinen Wald etwas engagieren können. Nein, er hat es nicht getan. Was hat er sich dabei gedacht? Vielleicht sagte er sich: Zwei Lausbuben der eine zündelt, aber der andere tritt das Feuer wieder aus. Also geht am Ende alles in Ordnung; kein Grund zum Eingreifen. Bei Feuer nicht mitzuhelfen, ist zwar grob unmoralisch; nichtsdestoweniger kann es auch als legitim gelten, entspricht es doch dem Verhalten des Schöpfers, der es ja in der Regel seiner Schöpfung überlässt, sich selbst zu ordnen. Indem sie das auch tut, trifft er so immer das Richtige.

Nun zur Vorratsdatenspeicherung. Sie ist sehr umstritten. Die Telekommunikationsunternehmen speichern unter anderen die anfallenden Verbindungsdaten ihrer Kunden für ihre eigenen legitimen Zwecke, Rechnungstellung etc. Das tun sie zweckbestimmt und zeitlich begrenzt. Polizei und Sicherheitsbehörden dürfen laut Gesetz bei gegebenem Anlass auf diese Daten zugreifen. Doch die dazu notwendige Speicherungsdauer ist ihnen zu kurz. Sie möchten die Daten für längere Zeit zur Verfügung haben. Zudem wollen sie auch ohne zu dokumentierenden Anlass abfragen können. Sie möchten die Telekommunikationsunternehmen zu einer ausreichend langen Speicherung verpflichtet wissen. Davon versprechen sie sich selbst mehr Flexibilität für ihre Aufgabenerfüllung und damit den Bürgern mehr Schutz vor Verbrechen und Terrorismus. Ihre Gegner halten jedoch eine solche anlasslose, massive Datenspeicherung für gesetzeswidrig; darüber hinaus für unverhältnismäßig, unnötig, für die Verbrechensprävention ungeeignet, insgesamt nicht zielführend, es sei denn auf den Weg in den Überwachungstaat. Doch die für Sicherheit Verantwortlichen fühlen sich kompetent genug, selber zu wissen, was sie brauchen. Um das zu bekommen, erwarten sie von der Legislativen und der Regierung eine hilfreiche Regelung. Sie bauen dabei auf die Sympathien des um seine Sicherheit besorgten Wählervolks. Aber die Gegenpartei hat die Sympathie der Judikativen gefunden. Das Bundesverfassungsgericht und der Europäische Gerichtshof haben gegen die Vorratsdatenspeicherung entschieden. Trotzdem schwelt unter dem Eindruck des gesteigerten Terrorismus der Streit weiter; die einen streiten für Sicherheit; die anderen für informationelle Selbstbestimmung; für die Vorratsdatenspeicherung um ein Sicherheitsinkrement; gegen Vorratsdatenspeicherung um die Vermeidung eines Freiheitsdekrements.

Was, liebe Leserinnen und Leser, sagt dazu der alte Herr Oberförster? Er steht - wie in der obigen Geschichte - am Rande des aktuellen Geschehens. Er greift nicht ein, zumindest nicht so, dass es die Streitenden merken könnten. Er spricht zu sich selbst; man hört nicht, was er spricht. Vielleicht sagt er sich: Sie haben beide Recht und tun recht, indem dass sie darum miteinander streiten. Sollen sie doch streiten und im Streit auf neue Ideen kommen, bevor ihnen die Zündhölzer dafür ausgehen.

Mit freundlichen Grüßen, Ihr

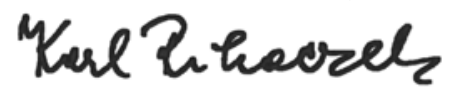

